\title{
Relação entre os níveis de lisina da dieta e as características de desempenho de codornas de corte EV2, durante o período de crescimento
}

\author{
[Relationship between lysine level in the diets and performance of EV2 meat-type quails \\ during the growing period] \\ G.S.S. Corrêa $a^{1,5}$, M.A. Silva $a^{2,5}$, A.B. Corrêa $a^{3}$, D.O. Fontes ${ }^{2}$, N.J.L. Dionello ${ }^{4,5}$, G.G. Santos ${ }^{3}$, \\ R.R. Wenceslau ${ }^{3}$, V.P.S. Felipe ${ }^{3}$, L.S. Freitas ${ }^{3}$ \\ ${ }^{1}$ Pós-doutoranda - EV-UFMG - Belo Horizonte, MG \\ ${ }^{2}$ Escola de Veterinária - UFMG - Belo Horizonte, MG \\ ${ }^{3}$ Aluno de pós-graduação - EV-UFMG - Belo Horizonte, MG \\ ${ }^{4}$ Departamento de Zootecnia - FAEM-UFPel - Pelotas, RS \\ ${ }^{5}$ Bolsista do $\mathrm{CNPq}$ \\ RESUMO
}

\begin{abstract}
Estudou-se a exigência de lisina total para a linha EV2 de codornas de corte na fase de crescimento. Foram utilizadas 312 codornas de corte EV2, de ambos os sexos, em delineamento experimental inteiramente ao acaso, cujos tratamentos consistiram de dietas com seis níveis lisina total - 1,4; 1,5; 1,6; 1,$7 ; 1,8$ e 1,9\% - e quatro repetições de 13 codornas por unidade experimental. Para avaliação do desempenho, estudaram-se peso corporal ao final de cada período (g), ganho de peso ( $\mathrm{g}$ ), consumo alimentar (g) e conversão alimentar (g de alimento/g de peso) durante os períodos experimentais inicial (nascimento ao $21^{\circ}$ ) e total (nascimento ao $42^{\circ}$ dia de idade). No período inicial, houve efeito significativo dos níveis de lisina total da dieta sobre o peso corporal, ganho de peso, consumo e conversão alimentar, com máximo desempenho das codornas nos níveis de 1,66;1,66;1,40 e 1,59\% de lisina total, respectivamente. Para o período total de criação, houve também efeito quadrático dos níveis de lisina da dieta sobre o peso corporal ao $42^{\circ}$ dia, ganho de peso, consumo e conversão alimentar, com os pontos de máximo desempenho estimados em 1,62;1,62;1,60 e 1,61\%, respectivamente. A exigência de lisina total para o máximo ganho de peso de machos e fêmeas de codornas de corte do nascimento ao $21^{\circ}$ dia é estimada em $1,66 \%$ e do nascimento ao $42^{\circ}$ dia de idade, em $1,62 \%$ da dieta.
\end{abstract}

Palavras-chave: codorna, exigência nutricional, ganho de peso, consumo alimentar, conversão alimentar, lisina total

\begin{abstract}
The total lysine requirements for EV2 meat-type quails during the growing phase were evaluated in a completely randomized experimental design, using 312 quails of both genders, with six levels of total lysine $(1.4 ; 1.5 ; 1.6 ; 1.7 ; 1.8$; and 1.9\%), four replicates of thirteen quails per experimental unit. Body weight $(g)$, weight gain $(g)$, feed intake $(g)$, and feed:weight gain ratio were recorded for all the experiment and growing period (initial - from birth to 21 days and total - from birth to 42 days of age). Significant effects of total lysine level on body weight, weight gain, feed intake, and feed:weight gain ratio were observed from birth to 21 days of age, with maximum performance for quails fed 1.66; 1.66; 1.40; and $1.59 \%$ of total lysine in the diets, respectively. Quadratic effects of total lysine level on body weight at 42 days of age and weight gain, feed intake, and feed:weight gain ratio, were observed with estimated maximum performance for quails fed 1,62; 1.62; 1.60; and 1.61\% of total lysine in the diets, respectively. The total lysine requirement for maximum weight gains for males and females from birth to 21 days of age was estimated in $1.66 \%$ and from birth to 42 days of age in $1.62 \%$ of the diet.
\end{abstract}

Keywords: quail, nutritional requirement, weight gain, feed intake, feed:weight gain ratio, total lysine

Recebido em 5 de julho de 2009

Aceito em 12 de julho de 2010

E-mail: gerusacorrea@hotmail.com.br 


\section{INTRODUÇÃO}

No progresso da coturnicultura de corte, a nutrição tem considerável responsabilidade, principalmente porque a alimentação de codornas representa cerca de 65 a $70 \%$ do custo de produção, sendo a proteína e/ou aminoácidos responsáveis por cerca de $25 \%$ deste custo. Assim, a nutrição deve contribuir para a melhoria do rendimento de carcaça, especialmente de carne de peito, que representa a parte nobre da carcaça das codornas.

Para a elaboração de programa nutricional para codornas de corte, o nutricionista baseia-se nas recomendações do NRC (Nutrient...,1994) que são elaboradas para atender às exigências de codornas japonesas com peso corporal menor que o das codornas de corte. Essas exigências são baseadas em resultados de experimentos realizados há mais de 15 anos e em codornas com potencial genético diferente das criadas atualmente (Corrêa et al., 2007c; 2007d).

Entretanto, quando se trabalham com diferentes grupos genéticos de codornas destinadas à produção de carne, em especial a carne de peito, a lisina é o principal nutriente, pois este aminoácido tem função quase que exclusivamente de síntese de proteína.

A lisina é geralmente tida como aminoácido referência na nutrição de monogástricos. Conforme Parksons e Baker (1994), mais informações estão disponíveis para lisina, comparada a outros aminoácidos para aves, porque ela apresenta função quase exclusiva de deposição proteica. A determinação da lisina é simples e direta, além de existirem informações de sua concentração e digestibilidade nos alimentos e o estabelecimento da exigência de outros aminoácidos da dieta em relação ao nível de lisina da dieta.

Svacha et al. (1970), ao estudarem exigências em lisina, metionina e glicina para codornas japonesas em dois períodos de crescimento (uma a três e quatro a cinco semanas de idade), verificaram que, no primeiro período, foram necessários $1,37 \%$ de lisina, $0,74 \%$ de aminoácidos sulfurosos e $1,74 \%$ de glicina e, no segundo período, os níveis de $1,20 \%$ de lisina, $0,72 \%$ de aminoácidos sulfurosos e $1,17 \%$ de glicina.
Ao utilizarem dietas à base de lisina digestível, Han e Baker (1994) recomendaram 0,85\% para o máximo ganho de peso e $0,89 \%$ de lisina digestível para frangos de corte para a conversão alimentar na fase de crescimento. Contrariamente, Conhalato et al. (1999), ao estudarem as exigências de lisina digestível em frangos do $22^{\circ}$ ao $42^{\circ}$ dia, concluíram que, para ganho de peso, o melhor nível foi de $1,02 \%$ e para conversão alimentar foi de $0,98 \%$. Para rendimento de carcaça, peito e pernas, os autores não encontraram diferenças estatísticas ao utilizarem dietas com níveis de 0,80 a $1,02 \%$ de lisina digestível.

Portanto, este trabalho teve como objetivo estudar o efeito de diferentes níveis de lisina total sobre o desempenho de codornas de corte, do grupo genético EV2, durante o período de crescimento.

\section{MATERIAL E MÉTODOS}

Foram adotadas para as análises dois períodos de criação: inicial (nascimento ao $21^{\circ}$ dia de idade) e total (nascimento ao $42^{\circ}$ dia de idade).

Foram utilizadas 312 codornas de corte EV2, de ambos os sexos, com um dia de idade, peso médio inicial de $8,0 \mathrm{~g}$, as quais foram alojadas em baterias de arame galvanizado com dimensões de $0,82 \mathrm{~m}$ de largura $\mathrm{x} 0,41 \mathrm{~m}$ de profundidade $\mathrm{x}$ $0,27 \mathrm{~cm}$ de altura por unidade experimental, equipadas com bebedouro copo e comedouro tipo calha.

$\mathrm{O}$ delineamento experimental foi o inteiramente ao acaso, com seis tratamentos (seis níveis de lisina total: 1,$4 ; 1,5 ; 1,6 ; 1,7 ; 1,8 ; 1,9 \%)$, e quatro repetições de 12 codornas por unidade experimental. Os níveis de lisina foram propostos segundo resultados encontrados por Corrêa et al. (2007d), os quais estimaram exigência de proteína bruta para máximo ganho de peso em codornas de corte em $30 \%$, o que corresponde ao nível de $1,65 \%$ de lisina total. Este nível (aproximado) de 1,60\% serviu de base para a formulação das dietas experimentais que continham 1,$4 ; 1,5 ; 1,6 ; 1,7 ; 1,8 ; 1,9 \%$ de lisina total. Dessa forma, foram utilizados três níveis acima e dois abaixo da exigência preconizada por Corrêa et al. (2007d). 
Assim, a dieta basal (Tab. 1) foi formulada para atender às exigências de proteína bruta, estabelecidas por Corrêa et al. (2007d), metionina + cistina, estabelecido por Corrêa et al. (2006), os quais observaram melhores ganhos de peso quando codornas de corte foram alimentadas com dietas contendo $0,93 \%$ de metionina + cistina e lisina (objeto deste estudo). As demais dietas experimentais foram obtidas pela suplementação de L-lisina na dieta basal, em substituição ao amido de milho. Os demais aminoácidos foram suplementados na medida do necessário para manter constante a relação preconizada pelo NRC (Nutrient..., 1994), entre cada um dos aminoácidos: metionina (73\%), treonina (78\%), valina (73\%), isoleucina (75\%), arginina (96\%) e fenilalanina $(74 \%)$ e $\mathrm{o}$ aminoácido lisina. A composição dos ingredientes seguiu a tabelas de Rostagno et al. (2000).

O desempenho foi avaliado pelo peso ao final de cada período (g), ganho de peso (g), consumo de ração (g/ave) e conversão alimentar ( $\mathrm{g}$ de dieta/g de peso) nos períodos inicial (do nascimento ao $21^{\circ}$ dia) e total (nascimento ao $42^{\circ}$ dia de idade).

As análises dos dados foram realizadas por meio do programa SAEG (Sistema...2004). As exigências de lisina foram obtidas regredindo-se as variáveis respostas em relação aos níveis de lisina em seus componentes lineares e quadráticos, para escolha do modelo de regressão que melhor descrevesse as observações.

Tabela 1. Composição percentual e calculada das dietas experimentais

\begin{tabular}{|c|c|c|c|c|c|c|}
\hline \multirow{2}{*}{ Ingrediente $(\%)$} & \multicolumn{6}{|c|}{ Nível de lisina (\%) } \\
\hline & 1,40 & 1,50 & 1,60 & 1,70 & 1,80 & 1,90 \\
\hline Milho & 46,597 & 46,597 & 46,597 & 46,597 & 46,597 & 46,597 \\
\hline Farelo de soja & 46,133 & 46,133 & 46,133 & 46,133 & 46,133 & 46,133 \\
\hline Amido & 2,400 & 2,105 & 1,749 & 1,312 & 0,808 & 0,206 \\
\hline Óleo de soja & 1,728 & 1,728 & 1,728 & 1,728 & 1,728 & 1,728 \\
\hline Calcário & 1,052 & 1,052 & 1,052 & 1,052 & 1,052 & 1,052 \\
\hline Fosfato bicálcico & 0,945 & 0,945 & 0,945 & 0,945 & 0,945 & 0,945 \\
\hline Premix $^{1}$ & 0,500 & 0,500 & 0,500 & 0,500 & 0,500 & 0,500 \\
\hline Sal comum & 0,262 & 0,262 & 0,262 & 0,262 & 0,262 & 0,262 \\
\hline DL-metionina & 0,265 & 0,339 & 0,412 & 0,486 & 0,560 & 0,634 \\
\hline L-lisina & - & 0,127 & 0,255 & 0,383 & 0,510 & 0,638 \\
\hline Treonina & 0,117 & 0,196 & 0,275 & 0,354 & 0,434 & 0,513 \\
\hline Valina & - & - & - & 0,071 & 0,140 & 0,214 \\
\hline Isoleucina & - & 0,015 & 0,091 & 0,167 & 0,242 & 0,318 \\
\hline Arginina & - & - & - & - & 0,004 & 0,101 \\
\hline Fenilalanina & - & - & - & 0,009 & 0,084 & 0,158 \\
\hline \multicolumn{7}{|l|}{ Composição calculada } \\
\hline Proteína bruta (\%) & 25,29 & 25,29 & 25,29 & 25,29 & 25,29 & 25,29 \\
\hline $\begin{array}{l}\text { Energia metabolizável } \\
(\mathrm{kcal} / \mathrm{kg})\end{array}$ & 2,900 & 2,900 & 2,900 & 2,900 & 2,900 & 2,900 \\
\hline Cálcio (\%) & 0,800 & 0,800 & 0,800 & 0,800 & 0,800 & 0,800 \\
\hline Fósforo disponível (\%) & 0,300 & 0,300 & 0,300 & 0,300 & 0,300 & 0,300 \\
\hline Sódio $(\%)$ & 0,150 & 0,150 & 0,150 & 0,150 & 0,150 & 0,150 \\
\hline \multicolumn{7}{|l|}{ Aminoácidos totais } \\
\hline Lisina $(\%)$ & 1,400 & 1,500 & 1,600 & 1,700 & 1,800 & 1,900 \\
\hline Metionina + cistina (\%) & 0,929 & 1,095 & 1,168 & 1,241 & 1,314 & 1,387 \\
\hline Triptofano (\%) & 0,328 & 0,328 & 0,328 & 0,328 & 0,328 & 0,328 \\
\hline Arginina (\%) & 1,724 & 1,724 & 1,724 & 1,724 & 1,728 & 1,824 \\
\hline Isoleucina (\%) & 1,110 & 1,125 & 1,200 & 1,275 & 1,350 & 1,425 \\
\hline Valina $(\%)$ & 1,171 & 1,171 & 1,171 & 1,241 & 1,314 & 1,387 \\
\hline Fenilalanina $(\%)$ & 1,249 & 1,249 & 1,249 & 1,258 & 1,332 & 1,406 \\
\hline Treonina $(\%)$ & 1,092 & 1,170 & 1,248 & 1,326 & 1,404 & 1,482 \\
\hline
\end{tabular}

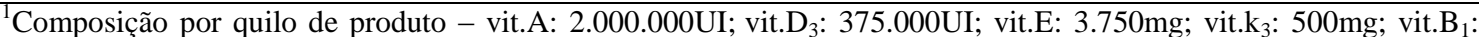
$250 \mathrm{mg}$; vit. $\mathrm{B}_{2}: 750 \mathrm{mg}$; vit. $\mathrm{B}_{6}: 500 \mathrm{mg}$; vit. $\mathrm{B}_{12}: 3.750 \mathrm{mcg}$; niacina: $6.250 \mathrm{mg}$; ac. Pantotênico: $2.500 \mathrm{mg}$; biotina: 10mg; ac. Fólico: $125 \mathrm{mg}$; colina: $75.000 \mathrm{mg}$; selênio: 45mg; iodo: $175 \mathrm{mg}$; ferro: $12.525 \mathrm{mg}$; cobre: $2.500 \mathrm{mg}$; manganês: $19.500 \mathrm{mg}$; zinco: $13.750 \mathrm{mg}$; avilamicina: $15.000 \mathrm{mg}$; narasin: $12.250 \mathrm{mg}$; B.H.T.: 500mg; vit.C: $12.500 \mathrm{mg}$. 


\section{RESULTADOS E DISCUSSÃO}

No período inicial de desenvolvimento das codornas, houve efeito significativo dos níveis de lisina total da dieta sobre o peso corporal, ganho de peso, consumo e conversão alimentar (Tab. 2), segundo as equações: $\hat{Y}_{i}=-251,31+468,17$
$\mathrm{X}_{\mathrm{i}}-141,33 \mathrm{X}_{i}^{2}$ (Fig. 1), $\hat{Y}_{i}=-255,14+462,01$

$\mathrm{X}_{\mathrm{i}}-139,49 \mathrm{X}_{i}^{2}$ (Fig. 2), $\hat{Y}_{i}=200,82+33,26 \mathrm{X}_{\mathrm{i}}$ e $\hat{Y}_{i}=6,60-5,78 \mathrm{X}_{\mathrm{i}}+1,82 \mathrm{X}_{i}^{2}$ (Fig. 3), com máximo desempenho das codornas nos níveis de 1,$66 ; 1,66 ; 1,40$ e $1,59 \%$ de lisina total, respectivamente.

Tabela 2. Peso final, ganho de peso, consumo e conversão alimentar das codornas de corte do nascimento ao $21^{\circ}$ dia de idade, em função dos níveis de lisina das dietas

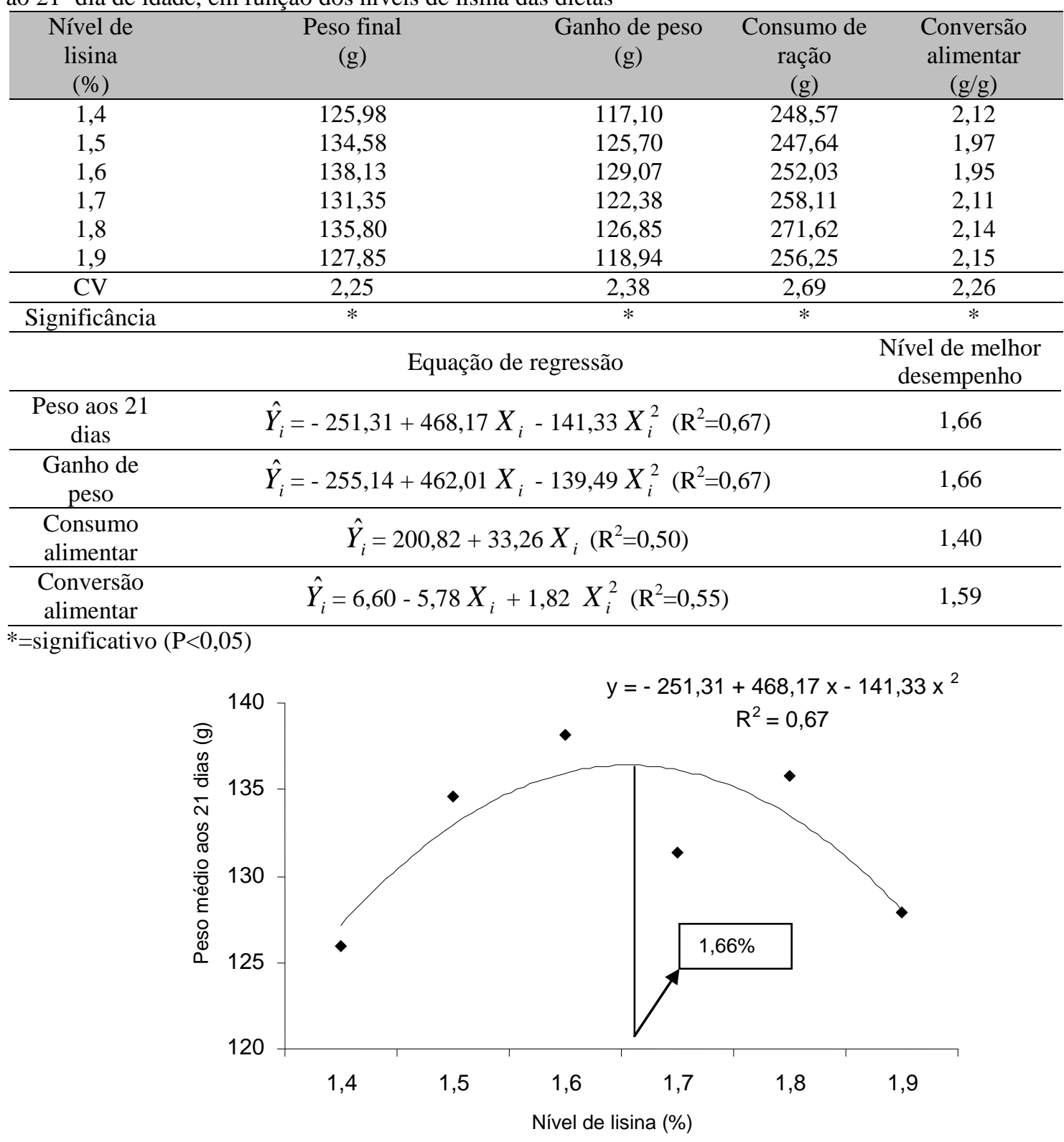

Figura 1. Regressão do peso no $21^{\circ}$ dia de idade de codornas de corte EV2 em relação ao nível de lisina da dieta. 


\section{Corrêa et al.}

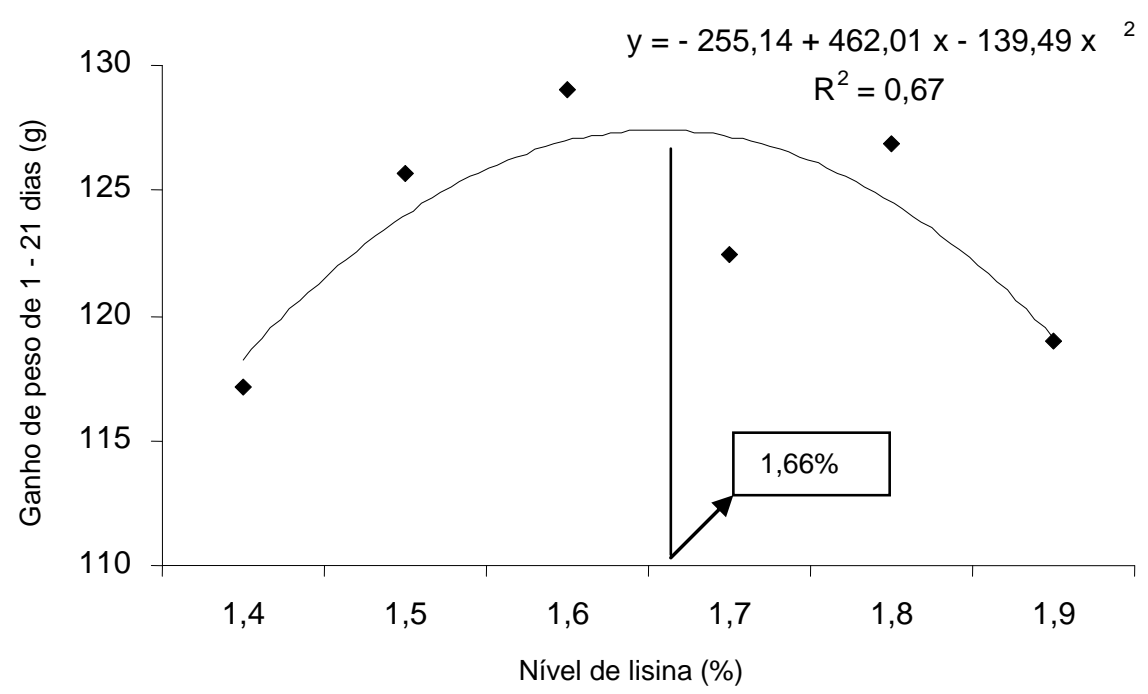

Figura 2. Regressão do ganho de peso do $1^{\circ}$ ao $21^{\circ}$ dia de idade de codornas de corte EV2 em relação ao nível de lisina da dieta.

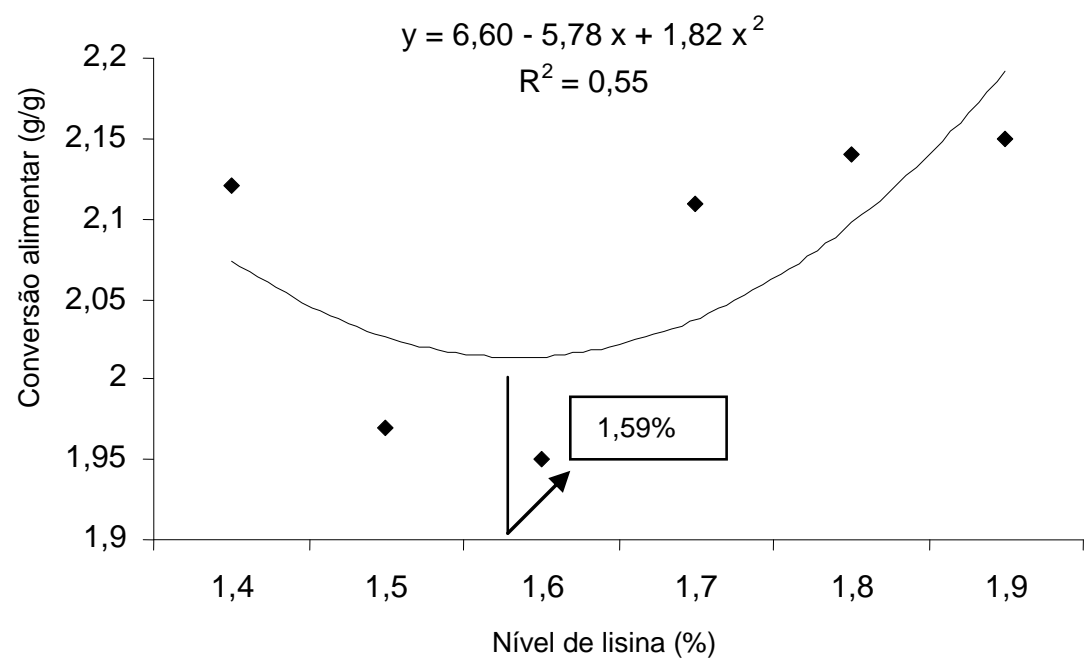

Figura 3. Regressão da conversão alimentar do $1^{\circ}$ ao $21^{\circ}$ dia de idade de codornas de corte EV2 em relação ao nível de lisina da dieta.

As exigências de 1,40 e 1,59\% estimadas para consumo e conversão alimentar foram menores que os $1,66 \%$, estimados para melhores pesos e ganhos de peso. Assim, pode-se observar que os níveis mais altos de lisina total, utilizados neste experimento, não foram suficientes para causar redução no consumo alimentar. Resultados semelhantes, apesar de em espécies distintas, foram observados por Schuermann et al. (1995) que encontraram menores estimativas das exigências para conversão alimentar do que para ganho de peso do nascimento ao $21^{\circ}$ dia de idade, em frangos de corte.

Estes resultados assemelham-se aos de Fisher (1994), citado por Barbosa et al. (2001), que afirmaram que, além de o efeito do incremento dos níveis de aminoácidos dietéticos ser progressivo sobre o desempenho das aves, eles seguem uma hierarquia, a saber: exigência para o máximo crescimento, exigência para a melhor conversão alimentar, exigência para melhor 
carcaça com menos gordura, exigência para ótima composição de carcaça e exigência para maior peso de peito.

Corrêa et al. (2007a), também, ao trabalharem com codornas de corte, encontraram máximo ganho de peso no período do nascimento ao $21^{\circ}$ dia de idade quando forneciam dietas contendo $1,75 \%$ de lisina total. Portanto, estes resultados indicam que a utilização de níveis de lisina total maiores do que os estabelecidos nas principais tabelas de exigência para codornas seria benéfica para as codornas de corte, pois estas apresentam maiores taxas de crescimento do que as codornas japonesas e, consequentemente, maior exigência de lisina total é esperada, já que este aminoácido está diretamente ligado à formação de massa muscular.

Svacha et al. (1970), ao estudarem as exigências nutricionais em lisina, metionina e glicina do nascimento à terceira semana de idade, verificaram que foram necessários $1,37 \%$ de lisina, 0,74\% de aminoácidos sulfurosos e 1,74\% de glicina para máximo ganho de peso de codornas japonesas.

O peso corporal no $42^{\circ}$ dia de idade, ganho de peso, consumo e conversão alimentar do nascimento ao $42^{\circ}$ dia de idade (Tab. 3) foram influenciados de forma quadrática pelos níveis de lisina total da dieta, segundo as equações: $\hat{Y}_{i}=-$ $316,83+696,99 X_{i}-215,27 X_{i}^{2}$ (Fig.4), $\hat{Y}_{i}=-$ $320,67+690,82 X_{i}-213,43 X_{i}^{2}$ (Fig. 5), $\hat{Y}_{i}=$ 1744,34-1179,44 $\mathrm{X}_{\mathrm{i}}+367,60 \mathrm{X}_{i}^{2}$ (Fig. 6) e $\hat{Y}_{i}$ $=15,91-15,58 \mathrm{X}_{\mathrm{i}}+4,83 \mathrm{X}_{i}^{2}$ (Fig. 7), com os pontos de máximo desempenho estimados em 1,$62 ; 1,62 ; 1,60$ e $1,61 \%$, respectivamente. Portanto, pode-se perceber que os valores de exigência, durante o período total de criação, foram semelhantes para as três variáveis estudadas.

Tabela 3. Peso final, ganho de peso, consumo e conversão alimentar das codornas de corte do nascimento ao $42^{\circ}$ dia de idade, em função do nível de lisina da dieta

\begin{tabular}{ccccc}
$\begin{array}{c}\text { Nível de lisina } \\
(\%)\end{array}$ & $\begin{array}{c}\text { Peso final } \\
(\mathrm{g})\end{array}$ & $\begin{array}{c}\text { Ganho de } \\
\text { peso }(\mathrm{g})\end{array}$ & $\begin{array}{c}\text { Consumo de ração } \\
(\mathrm{g})\end{array}$ & $\begin{array}{c}\text { Conversão alimentar } \\
(\mathrm{g} / \mathrm{g})\end{array}$ \\
\hline 1,4 & 236,09 & 227,21 & 817,51 & 3,60 \\
1,5 & 243,63 & 234,76 & 790,05 & 3,36 \\
1,6 & 253,49 & 244,43 & 813,68 & 3,33 \\
1,7 & 240,41 & 231,44 & 790,40 & 3,41 \\
1,8 & 239,80 & 230,85 & 818,52 & 3,54 \\
1,9 & 231,61 & 222,70 & 828,64 & 3,72 \\
\hline $\mathrm{CV}$ & 1,09 & 1,13 & $*, 71$ & $*$ \\
\hline Significância & $*$ & $*$ & Equação de regressão & desempenho de melhor \\
\hline \multicolumn{7}{c}{ Peso aos 42 dias } & $\hat{Y}_{i}=-316,83+696,99 X_{i}-215,27 X_{i}^{2}\left(\mathrm{R}^{2}=0,74\right)$ & 1,62 \\
\hline Ganho de peso & $\hat{Y}_{i}=-320,67+690,82 X_{i}-213,43 X_{i}^{2}\left(\mathrm{R}^{2}=0,74\right)$ & 1,62 \\
\hline Consumo & $\hat{Y}_{i}=1744,34-1179,44 X_{i}+367,60 X_{i}^{2}\left(\mathrm{R}^{2}=0,55\right)$ & 1,60 \\
\hline alimentar & $\hat{Y}_{i}=15,91-15,58 X_{i}+4,83 X_{i}^{2}\left(\mathrm{R}^{2}=0,95\right)$ & 1,61 \\
\hline Conversão & alimentar & &
\end{tabular}

*=significativo $(\mathrm{P}<0,05)$ 


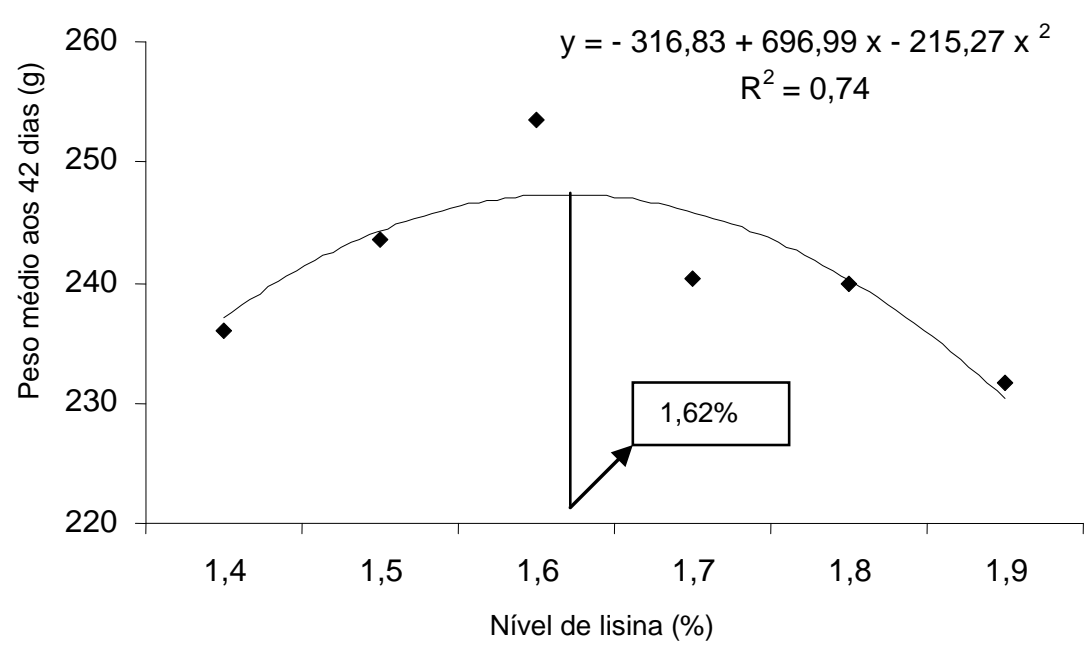

Figura 4. Regressão do peso médio aos $42^{\circ}$ dia de idade de codornas de corte EV2 em relação ao nível de lisina da dieta.

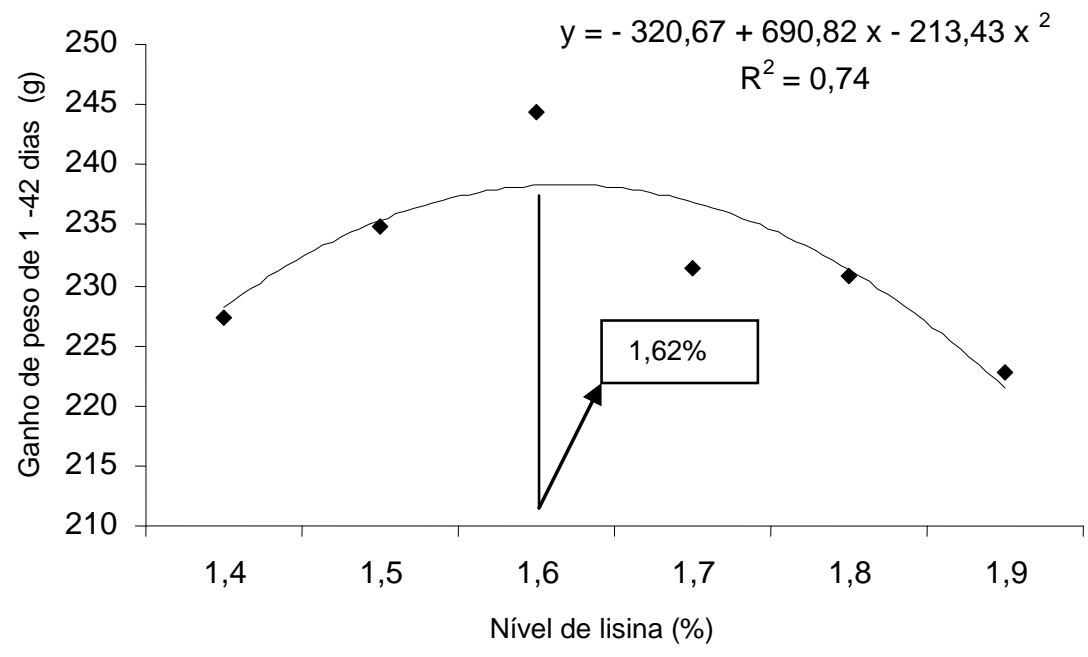

Figura 5. Regressão do ganho de peso do $1^{\circ}$ ao $42^{\circ}$ dia de idade de codornas de corte EV2 em relação ao nível de lisina da dieta.

As codornas alimentadas com dietas com níveis acima da exigência apresentaram menor desempenho porque, segundo Parr e Summers (1991), além da energia, o desequilíbrio entre aminoácidos exerce influência significativa sobre a ingestão e a conversão de alimentos e, como sugerido por Harper (1976), citado por Cabel et al. (1988), os aminoácidos presentes em uma dieta podem alterar o perfil aminoacídico plasmático e regular o balanço energético do animal. Em dietas desbalanceadas, o mecanismo que regula o consumo pode estar modificado, podendo ocorrer aumento na ingestão de alimento, em resposta à alteração no metabolismo energético ou em resposta à demanda crescente dos aminoácidos na ração. 
Relação entre os níveis de lisina...

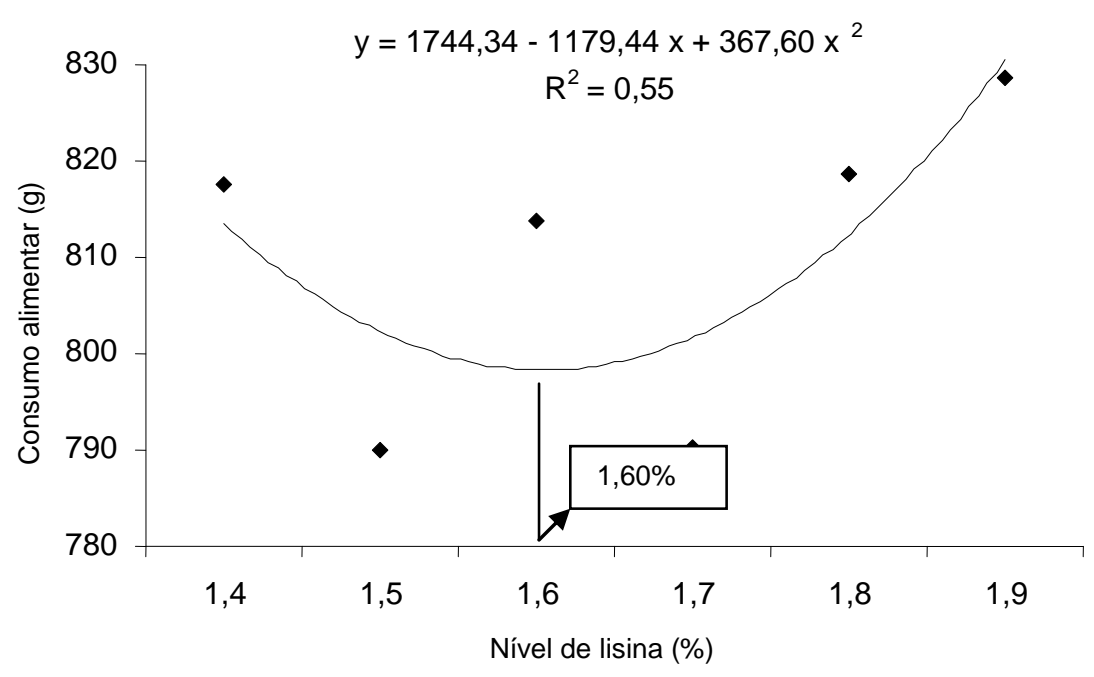

Figura 6. Regressão do consumo alimentar do $1^{\circ}$ ao $42^{\circ}$ dia de idade de codornas de corte EV2 em relação ao nível de lisina da dieta.

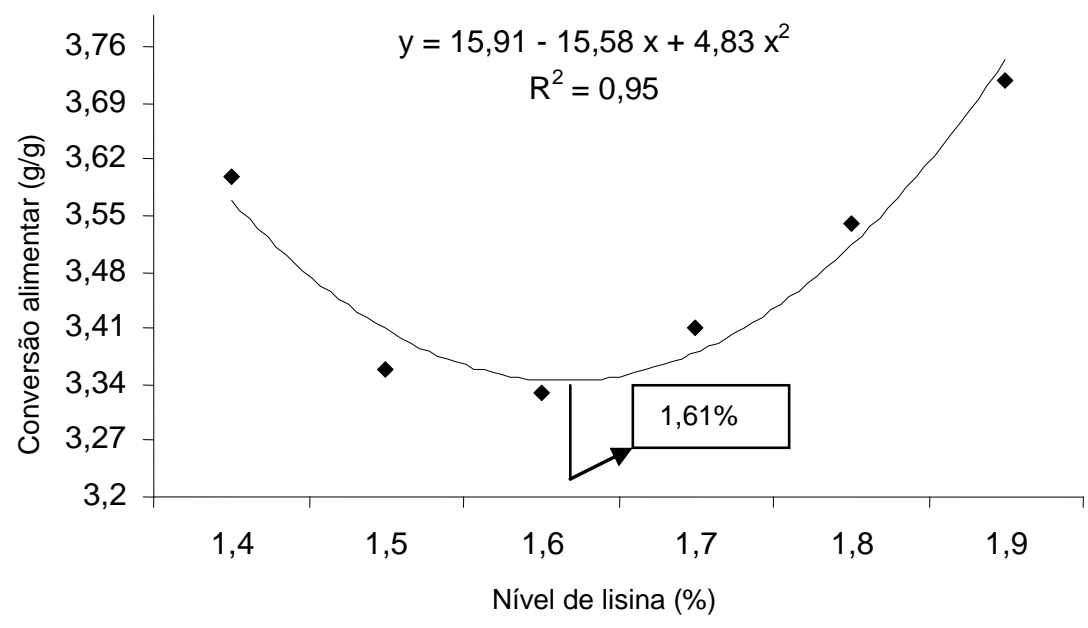

Figura 7. Regressão da conversão alimentar do $1^{\circ}$ ao $42^{\circ}$ dia de idade de codornas de corte EV2 em relação ao nível de lisina da dieta.

Mendes et al. (1997) e Valério et al (2003) não observaram diferença no consumo alimentar quando aumentavam os níveis de lisina da dieta de frangos em crescimento. Han e Baker (1994), ao utilizarem dietas à base de lisina digestível, recomendam $0,89 \%$ de lisina digestível com base na conversão alimentar e $0,85 \%$ para o máximo ganho de peso durante a fase de crescimento.

Corrêa et al. (2007a), também, ao trabalharem com codornas de corte, encontraram máximo ganho de peso no período do nascimento ao $42^{\circ}$ dia de idade quando forneciam dietas contendo $1,65 \%$ de lisina total. Os resultados sugerem que há diminuição no nível exigido de lisina para máximo desempenho das codornas de corte, com o avanço da idade, o que está relacionado ao menor ganho de peso observado na fase final de criação quando comparado à fase inicial, o que também foi observado para as exigências dos aminoácidos metionina + cistina, por Boomgaardt e Baker (1973) e Silva et al (1995), 
ao trabalharem com frangos de corte e por Corrêa et al. (2005; 2006), em codornas de corte. Entretanto, Graber et al. (1971) verificaram nível constante de exigência de aminoácidos com o avanço da idade e do peso dos frangos.

Observou-se, neste experimento, que codornas alimentadas com dietas contendo níveis de lisina acima dos recomendados não apresentaram melhora no desempenho, em virtude do excesso de aminoácidos, o que prejudicou o consumo alimentar.

\section{CONCLUSÕES}

A exigência de lisina total para o máximo ganho de peso de machos e fêmeas de codornas de corte EV2 em crescimento do nascimento ao $21^{\circ}$ dia de idade é estimada em $1,66 \%$ e do nascimento ao $42^{\mathrm{o}}$ dia de idade em $1,62 \%$ da dieta, correspondendo ao consumo de $0,213 \mathrm{~g}$ e $0,320 \mathrm{~g} / \mathrm{dia}$ de lisina/codorna, respectivamente.

\section{AGRADECIMENTOS}

Ao Conselho Nacional de Desenvolvimento Científico e Tecnológico - CNPq, pelo financiamento do projeto.

\section{REFERÊNCIAS BIBLIOGRÁFICAS}

BARBOSA, M.J.B.; JUNQUEIRA, O.M.; ANDREOTTI, M.O. et al. Desempenho e rendimento de carcaça de frangos de corte submetidos a diferentes níveis de treonina e lisina, na fase final de criação. Rev. Bras. Zootec., v.30, p.1476-1480, 2001.

BOOMGAARDT, J.; BAKER, D.H. Effect of age on the lysine and sulfur amino acid requirement of growing chickens. Poult. Sci., v.52, p.592-597, 1973.

CABEL, M.C.; GOODWIN, T.L.; WALDROUP, P.W. Feather meal as a nonspecific nitrogen source for abdominal fat resuction in broiler during the finishing period. Poult. Sci., v.67, p.300-306, 1988.

CONHALATO, G.S.; DONZELE, J.L.; ALBINO, L.F.T. et al. Níveis de lisina digestível para frangos de corte machos na fase de 21 a 42 dias de idade. Rev. Bras. Zootec., v.28, p.91-97, 1999.
CORRÊA, G.S.S.; SILVA, M. A.; CORRÊA, A.B. et al. Desempenho de codornas de corte EV1 alimentadas com diferentes níveis de lisina nas dietas. Arq. Bras. Med. Vet. Zootec., v.59, p.1545-1553, 2007a.

CORRÊA, G.S.S.; SILVA, M.A.; CORRÊA, A.B. et al. Exigência de metionina + cistina para codornas de corte em crescimento. Arq. Bras. Med. Vet. Zootec., v.58, p.414-420, 2006.

CORRÊA, G.S.S.; SILVA, M. A.; CORRÊA, A. B. et al. Exigência de proteína bruta e energia metabolizável para codornas de corte EV1. Arq. Bras. Med. Vet. Zootec., v.59, p.797-804, 2007c.

CORRÊA, G.S.S.; SILVA, M.A.; CORRÊA, A B. et al. Exigência de proteína bruta para codornas de corte EV1 em crescimento. Arq. Bras. Med. Vet. Zootec., v.59, p.1278-1286, 2007d.

CORRÊA, G.S.S.; SILVA, M.A.; CORRÊA, A.B. et al. Níveis de metionina + cistina para híbridos EV1 de codornas europeias no período de crescimento. In: REUNIÃO ANUAL DA SOCIEDADE BRASILEIRA DE ZOOTECNIA, 2005. Goiânia. Anais... Goiânia: SBZ, 2005.

GRABER, G.; SCOTT, H.M.; BAKER, D.H. Sulfur amino acid nutrition of the growing chick: Effect of age on the dietary methionine requirement. Poult. Sci., v.50, p.851-858, 1971.

HAN, Y.; BAKER, D.H. Digestible lysine requeriment of male and female broiler chicks during the period three to six weeks posthatching. Poult. Sci., v.73, p.1739-1745, 1994.

MENDES, A.A.; WATKINS, S. E.; ENGLAND, J. A. et al. Influence of dietary lysine levels and arginine:lysine ratios on performance of broilers exposed to heat or cold stress during the period of three to six weeks of age. Poult. Sci., v.76, p.472-481, 1997.

NUTRIENT requirements of poultry. 9.ed. Washington: National Academy of Sciences, 1994. p.44-45.

PARKSONS, C.M.; BAKER, D.II The concept and usage of ideal proteins in the feeding of nonruminantes. In: SIMPÓSIO INTERNACIONAL DE PRODUÇÃO DE NÃO RUMINANTES, 1994, Maringá. Anais... Maringá, 1994. p.119-128. 
PARR, J.F. SUMMERS, J.D. The effects of minimizing amino acid excess in broiler diets. Poult. Sci., v.70, p.1510-1519, 1991.

ROSTAGNO, H.S.; ALBINO, L.F.T.; DONZELE, J.L. et al. Tabelas Brasileiras para Aves e Suínos: composição de alimentos e exigências nutricionais. 2.ed. Viçosa: UFV, 2000. 141p.

SCHUERMANN, G.N.; MAIER, J.C.; BELLAVER, C. et al. Metionina e lisina no desenvolvimento de frangos de corte. Rev. Bras. Agrocienc., v.1, p.75-86, 1995.

SILVA, M.A.; ALBINO, L.F.T.; ROSTAGNO, H.S. et al. Efeito do nível de proteína bruta sobre as exigências em metionina + cistina para frangos de corte. In: CONFERÊNCIA APINCO DE CIÊNCIA E TECNOLOGIA AVÍCOLAS, 1995, Curitiba. Anais... Curitiba, 1995. p.41-42.
SVACHA, A.; WEBER. C.W.; REID, B.L. Lysine, methionine and glycine requirements of Japanese quail to five weeks og age. Poult. Sci., v.49, p.54-59, 1970.

SISTEMA de análises estatísticas e genéticas SAEG, Versão 9.0. Viçosa: UFV, 2004.

VALÉRIO, S.R.; OLIVEIRA, R.F.M.; DONZELE, J.L. et al. Níveis de lisina digestível em rações, mantendo ou não a relação aminoacídica, para frangos de corte de 22 a 42 dias de idade, sob condições de estresse por calor. Rev. Bras. Zootec., v.32, p.372-382, 2003. 